\title{
Wear Mechanism of Multi-layer AICrWN/AICrWSiN Coatings on Cemented Carbide Tool Prepared by Arc lon Plating in Dry Cutting of Sintered Steel
}

\author{
Tadahiro Wada $^{1}$ and Hiroyuki Hanyu ${ }^{2}$ \\ ${ }^{1}$ Nara National College of Technology, Department of Mechanical Engineering, 22 Yata-cho, Yamatokoriyama 639-1080, Japan \\ ${ }^{2}$ OSG Corporation,Japan
}

\begin{abstract}
To clarify the effectiveness of multi-layer AlCrWN/AlCrWSiN-coated cemented carbide tools, the wear progress was investigated in cutting sintered steel using three types of coated tool. Tool I had a monolayer (A160,Cr25,W15)N-coating film, Tool II had a mono-layer (A153,Cr23,W14,Si10)N-coating film and Tool III had a multi-layer (A160,Cr25,W15)N/(A153,Cr23,W14,Si10)N-coating film. The following results were obtained: (1) The main tool failure of the three types of coated tools was flank wear within a maximum value of flank wear width of $0.2 \mathrm{~mm}$. (2) The wear progress of Type III, which was a multi-layer coating system, was the slowest in cutting sintered steel.
\end{abstract}

\section{Introduction}

A machine part having a complicated shape can be accurately mass-produced by powder metallurgy, while a sintered material can be produced because it has a large degree of freedom in terms of material design. For dimensional accuracy, it is often necessary for sintered steel machine parts to be machined by a mass production metal removal process. The tool life in cutting sintered steel is shorter than that in cutting molten steel such as carbon steel. Moreover, as sintered machine parts are often cut at high cutting speed for mass-production, the tool materials must have effective wear resistance.

An aluminium-chromium based coating film has been developed. Comparing the performance of $\mathrm{AlCrN}$ coated tool inserts with that of TiN coated ones, the former can achieve approximately $33 \%$ more depth of cut and can attain higher cutting speed due to better thermal resistance of the coated inserts [1]. However, the results of our study indicate that the critical scratch load, which was the value measured by the scratch test, of the AlCrN coating film was $77 \mathrm{~N}$ and the micro-hardness was 2760 $\mathrm{HV}_{0.25 \mathrm{~N}}$. Therefore, in order to improve both the scratch strength and the micro-hardness of the AlCrN coating film, cathode material of an Al-Cr-W target was used in adding tungsten $(\mathrm{W})$ to the cathode material of the $\mathrm{Al}-\mathrm{Cr}$ target. As a result, the scratch strength and the microhardness of the AlCrWN coating film increased to $81 \mathrm{~N}$ and $3110 \mathrm{HV}_{0.25 \mathrm{~N}}$, respectively [2]. To improve the properties of the coating film, the cathode material of an Al-Cr-W-Si target was used [3-5]. For example, Yu-ping Feng et al. reported that the hardness of $\mathrm{AlCrSiWN}$ coating film is higher than that of $\mathrm{AlCrN}$ at temperatures below 700 degrees Celsius [3].
Many multi-layer coating materials to improve tool life have been developed [6-10]. The wear progress of the multi-layered AlCrWCN/AlCrWSiCN-coated tool was slower than that of the mono-layer AlCrWSiCN-coated tool in cutting hardened steel [11] or in milling hardened steel [12]. However, the properties of the multi-layer AlCrWN/AlCrWSiN-coated coating film have not been elucidated, and the tool wear of the multi-layer AlCrWN/AlCrWSiN-coated tool has not been clarified in cutting sintered steel.

In this study, to clarify the effectiveness of the multi-layer AlCrWN/AlCrWSiN-coated cemented carbide tool, the wear progress was investigated in cutting sintered steel using three types of coated tools.

\section{Experimental procedure}

The work material used was sintered steel. The chemical composition and properties of the sintered steel are shown in Table 1.

We measured the thickness, hardness and scratch strength (critical scratch load measured by a scratch tester) of various coating films formed on the surface of the substrate, which was a WC-Co cemented carbide ISO $\mathrm{K} 10$ by the arc ion plating process. Coating deposition was performed by an arc ion plating system (KOBE STEEL, LTD. AIP-S40).

Three types of PVD coated cemented carbides were used for the cutting material as shown in Table 2. Namely, the coating films used were $(\mathrm{A} 160, \mathrm{Cr} 25, \mathrm{~W} 15) \mathrm{N}$ and (A153,Cr23,W14,Si10)N coating film. Type I, which has the $(\mathrm{Al} 60, \mathrm{Cr} 25, \mathrm{~W} 15) \mathrm{N}$ coating film and Type II, which has the $(\mathrm{A} 153, \mathrm{Cr} 23, \mathrm{~W} 14, \mathrm{Si10}) \mathrm{N}$ coating film, are mono- 
layer coating systems. Type III is a multi-layer coating system.

The configurations of the tool inserts were ISO TNGA160408. The insert was attached to a tool holder MTGNR2525M16. In this case, the tool geometry was ($6,-6,6,6,29,-1,0.8 \mathrm{~mm})$.

The turning tests were conducted on a precision lathe (Type ST5, SHOUN MACHINE TOOL Co., Ltd.) by adding a variable-speed drive. The driving power of this lathe is $7.5 / 11 \mathrm{~kW}$ and the maximum rotational speed is $2500 \mathrm{~min}^{-1}$. Sintered steel was turned under the cutting conditions shown in Table 3, and the tool wear was investigated.

Table 1. Chemical composition and properties of sintered steel

\begin{tabular}{|c|c|c|c|c|}
\hline \multicolumn{5}{|c|}{ Chemical composition [mass \%] } \\
\hline $\mathrm{C}$ & $\mathrm{Cu}$ & $\mathrm{Ni}$ & $\mathrm{Mo}$ & $\mathrm{Fe}$ \\
\hline $0.3-0.7$ & $1-2$ & $3-5$ & $0.2-0.8$ & Bal. \\
\hline \multicolumn{5}{|c|}{ Properties } \\
\hline Hardness: $70 \mathrm{HRB}(129 \mathrm{HB})$ & Density: $7.1 \mathrm{Mg} / \mathrm{m}^{3}$ \\
\hline
\end{tabular}

Table 2. Tool material in turning of sintered steel

\begin{tabular}{|c|c|c|}
\hline Tool type & Coating layer(s) & \\
\hline Tool I* & $(\mathrm{Al} 60, \mathrm{Cr} 25, \mathrm{~W} 15) \mathrm{N}$ & \\
\hline Tool II* & (A153,Cr23,W14,Si10)N & \\
\hline Tool III** & $\begin{array}{l}\text { Substrate } \rightarrow \quad(\text { Al60,Cr25,W15)N } \\
(A 153, C r 23, W 14, \text { Si10)N } \\
(A 160, C r 25, W 15) \\
(A 153, C r 23, W 14, \text { Si10)N } \rightarrow \cdots \cdots\end{array}$ & \\
\hline
\end{tabular}

Substrate: Cemented carbide ISO K10

*: Mono-layer coating system, **: Multi-layer coating system

Table 3. Cutting conditions

\begin{tabular}{|l|l|}
\hline Cutting speed & $5.00 \mathrm{~m} / \mathrm{s}$ \\
\hline Feed speed & $0.2 \mathrm{~mm} / \mathrm{rev}$ \\
\hline Depth of cut & $0.1 \mathrm{~mm}$ \\
\hline Cutting method & Dry cutting \\
\hline
\end{tabular}

\section{Results and discussion}

In cutting sintered steel using three types of coated tools, tool wear was investigated. Figure 1 shows the tool wear in turning sintered steel with three types of coated tools at a cutting speed of $5.00 \mathrm{~m} / \mathrm{s}$, feed rate of $0.2 \mathrm{~mm} / \mathrm{rev}$ and cutting depth of $0.1 \mathrm{~mm}$. In the case of the three types of coated cemented carbide tools, there is a slight crater on the rake face, and there is no remarkable adhesion on either the rake face or flank as shown in Figure 1. Furthermore, no remarkable flaking of the coating layer is found.

The above results indicate that the main tool failure of the three types of coated tools was the flank wear within the maximum value of the flank wear width of 0.2 $\mathrm{mm}$. Therefore, the maximum value of the flank wear width (VBmax) was measured under a microscope.

Figure 2 shows the wear progress. As Figure 2 shows, (1) As compared with Type I and Type II, which are mono-layer coating systems, the wear progress of Type I is slower than that of Type II. Therefore, adding silicon ( $\mathrm{Si}$ ) to the AlCrWN coating film is not effective for improving the wear-resistance. (2) The wear progress of Type III, that is the multi-layer coating system, is slower than that of Type I or Type II. Therefore, the coating fil that has multiple layers of the AlCrWN coating film and AlCrWSiN coating film is effective for improving the wear-resistance.

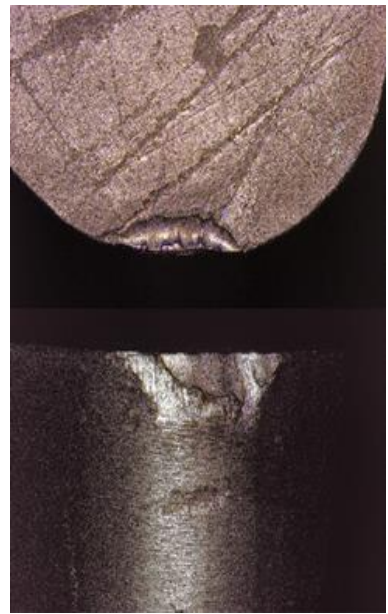

(a) Type I, L=0.9km

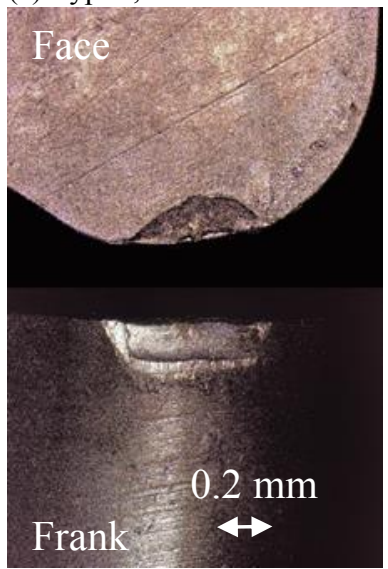

(c) Type III, L=1.0 km

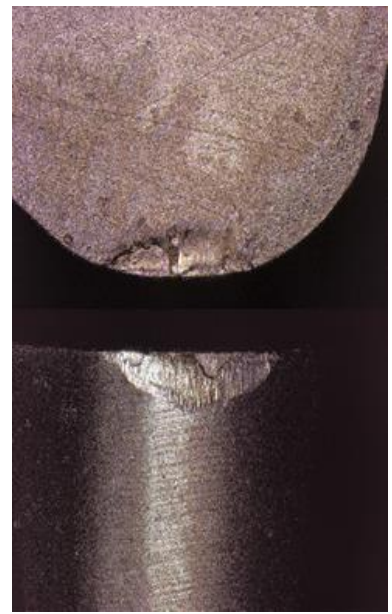

(b) Type II, L=0.5 km
Figure 1. Tool wear observed after turning sintered steel with three types of coated tools at a cutting speed of $5.00 \mathrm{~m} / \mathrm{s}$, feed rate of $0.2 \mathrm{~mm} / \mathrm{rev}$ and cutting depth of $0.1 \mathrm{~mm}$.

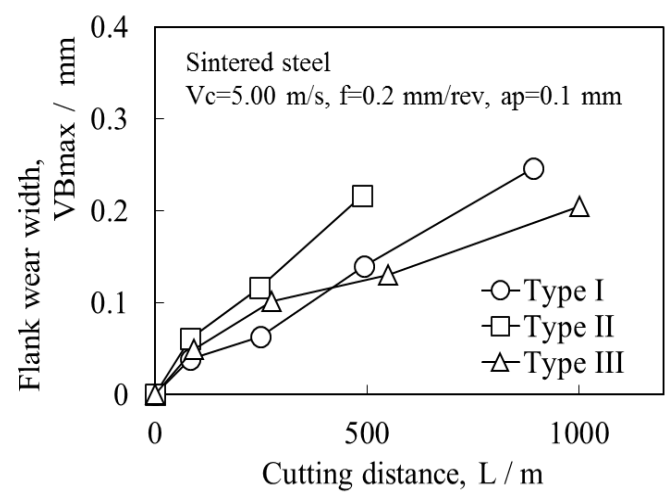

Figure 2. Wear progress of various coated cemented carbide. 
Figure 3 shows EDS mapping analysis on the abraded surface of the three types of coated tools. The elements analyzed are oxygen $(\mathrm{O})$ and iron $(\mathrm{Fe})$, and the $\mathrm{Fe}$ is the chemical composition of the sintered steel. As compared with the oxygen element on the abraded surface of the three types of coated tools, the oxygen element of the Type III coated tool, which was turned at a long cutting distance, is slightly less than that of the Type I or Type II coated tool. Therefore, the cutting temperature of the Type III coated tool was slightly lower than of the Type I or the Type II coated tool. So, the wear progress of the Type III coated tool was the slowest. Furthermore, when comparing the iron element of the three types of coating tools, the iron element on the abraded surface of the flank face of the Type III coated tool was less than that of the Type I or the Type II coated tool.

Therefore, the wear mechanism of the three types is both abrasive wear and adhesion wear. For abrasive wear, the wear-resistance of the coating film often depends on the hardness of the coating film. For adhesion wear, the wear-resistance of the coating film often depends on the scratch load between the substrate and the coating film. Therefore, the characteristics of the coating films were investigated.

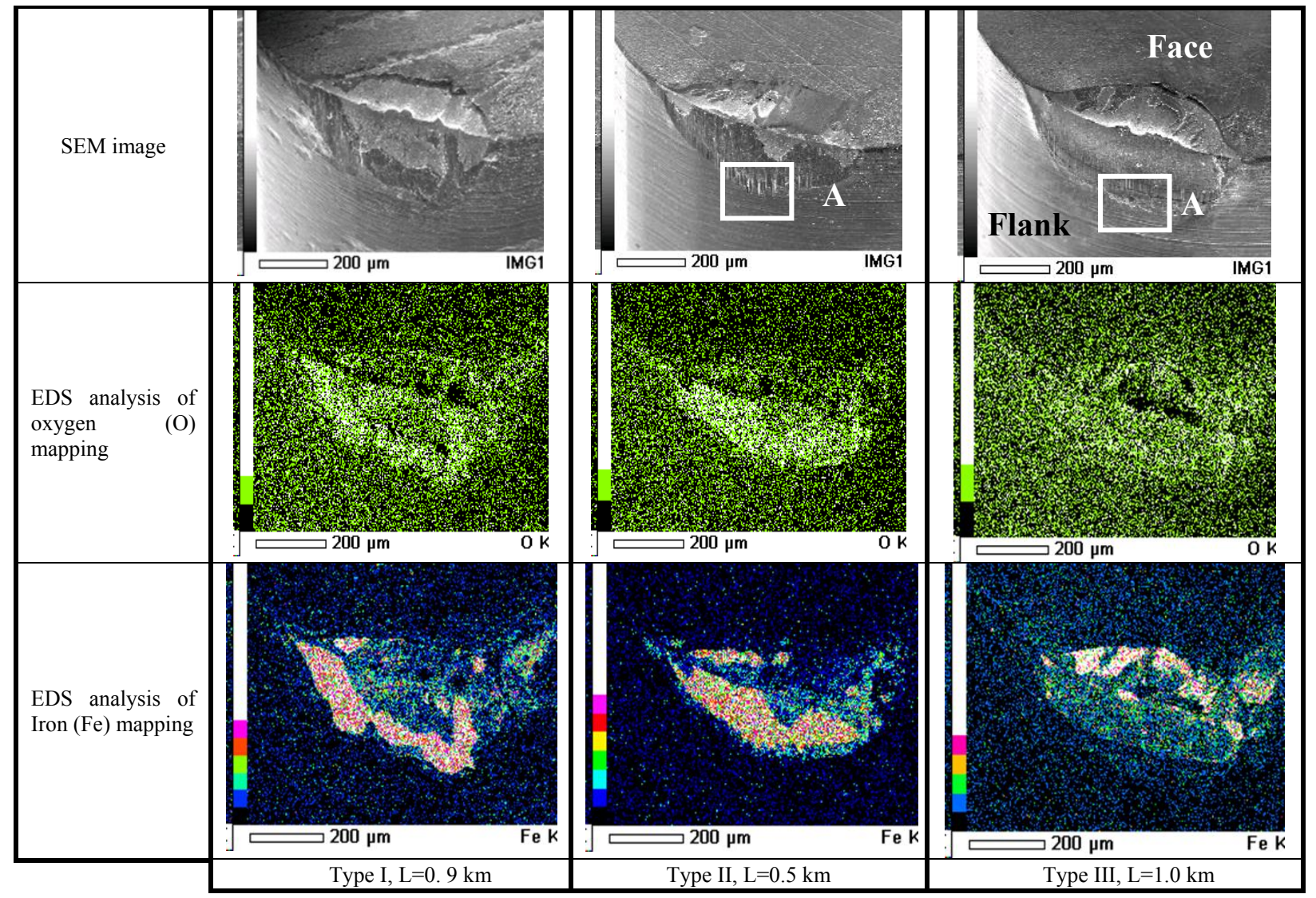

L:Cutting distance

Figure 3. SEM observation and EDS mapping analysis on the abraded surface of the Type I, Type II and Type III coated tool.

Table 4 shows the characteristics of coating films. Although the Type II coating film of $5.8 \mu \mathrm{m}$ is the thickest, the wear progress of Type II was the fastest. As compared with the two types of mono-layered coating system, namely Type I and Type II, the critical scratch load of Type I $81 \mathrm{~N}$ is lower than that of Type II over $130 \mathrm{~N}$, and the micro-hardness of Type I 3110 $\mathrm{HV}_{0.25 \mathrm{~N}}$ is higher than that of Type II $3010 \mathrm{HV}_{0.25 \mathrm{~N}}$. It seems that in the case of the mono-layer coating system, the micro-hardness of the coating film had a large influence on the wear progress. Therefore, the wear progress of Type I was slower than that of Type II.
On the other hand, although the critical scratch load of Type III is high, the coating film is the thinnest and the micro-hardness of Type III is the lowest. However, the wear progress of Type III was the slowest.

Table 4. Characteristics of coating films

\begin{tabular}{|c|c|c|c|}
\hline $\begin{array}{l}\text { Cutting } \\
\text { tool }\end{array}$ & $\begin{array}{l}\text { Thickness of } \\
\text { coating film } \\
{[\mu \mathrm{m}]}\end{array}$ & $\begin{array}{l}\text { Micro- } \\
\text { hardness } \\
{\left[\mathrm{HV}_{0.25 \mathrm{~N}}\right]}\end{array}$ & $\begin{array}{l}\text { Critical } \\
\text { scratch } \\
\text { load* }[N]\end{array}$ \\
\hline Type I & 4.4 & 3110 & 81 \\
\hline Type II & 5.8 & 3010 & $>130$ \\
\hline Type III & 2.5 & 3000 & $>130$ \\
\hline
\end{tabular}

*: Measured value by scratch test 


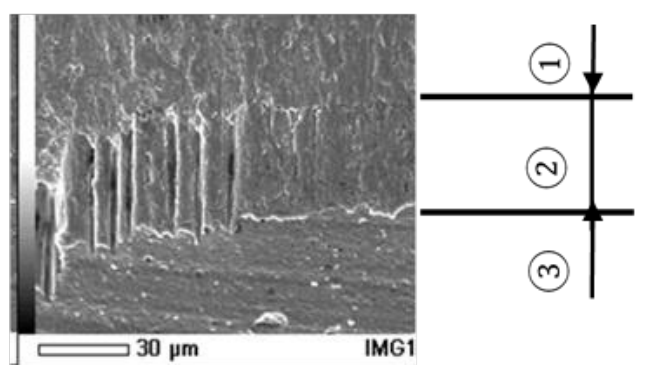

(a) Type II

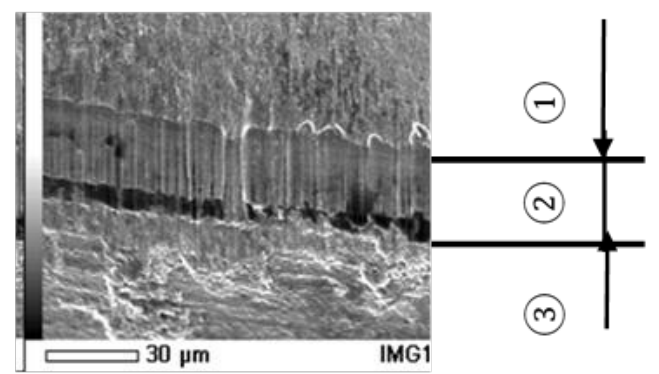

(b) Type III

(i) SEM image

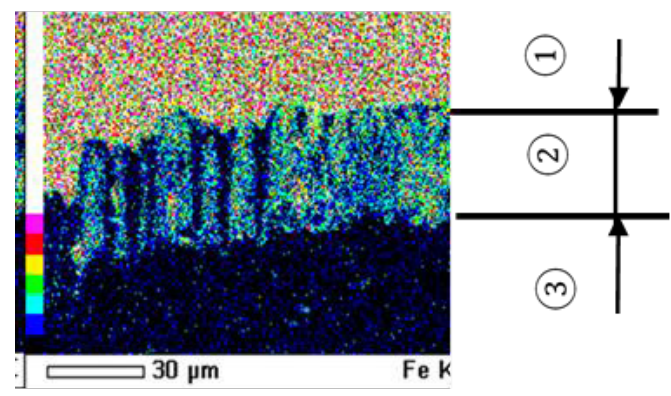

(a) Type II

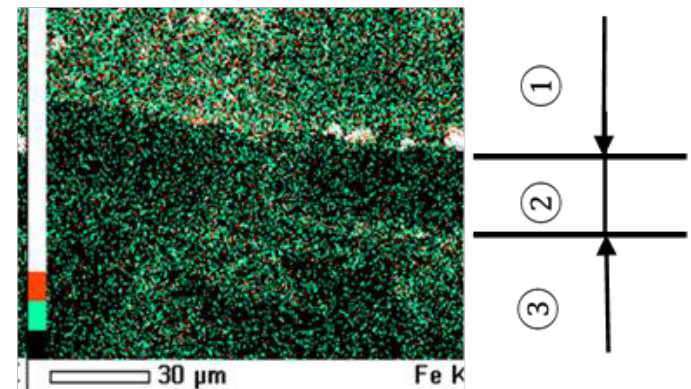

(b) Type III

(ii) EDS analysis of Fe mapping shown in Fig. (i)

(1): Abraded surface of substrate

(2): Abraded surface of coating film

(3): Surface of coating film

Figure 4. Details of "A" shown in Figure 3.

Although the mechanical properties of the Type II and that of the Type III coating film were almost the same as shown in Table 4, the wear progress of Type
III was slower than that of Type II. To clarify the reason for this, the abraded surface of the coating film was observed.

Figure 4 shows the details of "A" shown in Figure 3. In the case of Type III, many striate scratched by a hard material are evident on the abraded surface of the coating film indicated by "(2)" shown in Figure 4(i)(b). Furthermore, the Fe element indicated by "(2)" on the abraded surface of the coating film of the Type III coated tool is somewhat smaller than that of the Type II coated tool as shown in Figure 4(ii). Therefore, the main wear mechanism of the Type III coating film was abrasive wear. That is, by SEM observation, the tool wear mechanism of the Type III coating film was abrasive wear. On the other hand, the wear mechanism of the Type II coating film was a combination of abrasive wear and abrasion wear. Thus, the wear of Type II is larger than that of Type III.

\section{Conclusion}

In this study, to clarify the effectiveness of the multilayer AlCrWN/AlCrWSiN-coated cemented carbide tool, the wear progress was investigated in cutting sintered steel using three types of coated tools. Tool I had a mono-layer (A160,Cr25,W15)N-coating film, Tool II had a mono-layer (A153,Cr23,W14,Si10)Ncoating film and Tool III had a multi-layer (A160,Cr25,W15)N/ (Al53,Cr23,W14,Si10)N-coating film.

The following results were obtained:

(1) The main tool failure of the three types of coated tools was flank wear within the maximum value of the flank wear width of $0.2 \mathrm{~mm}$.

(2) The wear progress of Type III, which was the multi-layer coating system, was the slowest in cutting sintered steel.

\section{Acknowledgment}

This work was supported by JSPS (Japan Society for the Promotion of Science) KAKENHI Grant Number JP 17K06102 (Grant-in-Aid for Scientific Research (C)).

\section{References}

1. Yueh-Jaw Lin, Ashutosh Agrawal, Yunmei Fang: Wear progressions and tool life enhancement with AlCrN coated inserts in high-speed dry and wet steel lathing, Wear, Volume 264, Issues 3-4, pp. 226-234 (2008)

2. Tadahiro Wada, Hiroyuki Hanyu: Tool Wear of Aluminum/Chromium/Tungsten-based-coated Cemented Carbide in Cutting Hardened Steel, Applied Mechanics and Materials Vol. 798, pp. 377-383 (2015)

3. Yu-ping Feng, Li Zhang, Rong-xian Ke, Qing-lei Wan, ZheWanga, Zhi-hong Lu: Thermal stability and oxidation behavior of AlTiN, AlCrN and 
AlCrSiWN coatings, Int. Journal of Refractory Metals and Hard Materials, Vol. 43 March, pp. 241-249 (2014)

4. Shihong Zhang, Lei Wang, Qimin Wang, Mingxi Li: A superhard CrAlSiN superlattice coating deposited by multi-arc ion plating: I. Microstructure and mechanical properties, Surface \& Coatings Technology, 214, pp. 160-167(2013)

5. Lihui Zhu, Mingmei Hu, Wangyang Ni, Yixiong Liu: High temperature oxidation behavior of Ti0.5Al0.5N coating and Ti0.5A10.4Si0.1N coating, Vacuum, 86, pp. 1795-1799 (2012)

6. J.H. Hsieh, C. Liang, C.H. Yu, W. Wu: Deposition and characterization of TiAlN and multi-layered TiN/TiAlN coatings using unbalanced magnetron sputtering, Surface and Coatings Technology, 108-109, pp. 132-137 (1998)

7. A.A. Vereschaka, S.N. Grigoriev, A.S. Vereschaka, A.Yu. Popov and A. D. Batako: Nano-scale multilayered composite coatings for cutting tools operating under heavy cutting conditions, Procedia CIRP, 14, pp. 239-244 (2014)

8. Tsao Chung-Chen, Hocheng Hong: Comparison of the tool life of tungsten carbides coated by multi-layer TiCN and TiAlCN for end mills using the Taguchi method, Journal of Materials Processing Technology, Volume 123, Issue 1, pp. $1-4(2002)$

9. M. Nouari, A. Ginting: Wear characteristics and performance of multi-layer CVD-coated alloyed carbide tool in dry end milling of titanium alloy, Surface \& Coatings Technology, 200, pp. 5663$5676(2006)$

10. Q. Yang, R.McKellar: Nanolayered CrAlTiN and multilayered CrAlTiN-AlTiN coatings for solid particle erosion protection, Tribolo.gy International, 83, pp. 12-20 (2015)

11. Tadahiro Wada, Hiroyuki Hanyu: Tool Wear of Aluminum/Chromium/Tungsten/Silicon-BasedCoated Cemented Carbide Tools in Cutting of Hardened Steel, International Journal of Engineering and Technology, Vol. 8, No. 6, pp. 406-409 (2016)

12. Tadahiro Wada, Hiroyuki Hanyu: Tool Wear of Aluminum/Chromium/Tungsten/Silicon-basedcoated End Mill Cutters in Milling Hardened Steel, Proceedings of 3rd International Conference on Mechanical Properties of Materials (ICMPM 2016), December 14-17, Venice, Italy (PM008) (2016) 